\title{
State of Working Slum Children in Dhaka City
}

\author{
Md. Nurul Amin', Shayela Farah ${ }^{2}$, Mohoshina Karim ${ }^{3}$, Farhana Rahman, ${ }^{4}$ Shitil lbna Islam ${ }^{5}$
}

\begin{abstract}
Background \& objective: Rapid urbanisation in the $20^{\text {th }}$ century has been accompanied by the development of slums. Nearly one-third of the world's population and $>60 \%$ of urban populations in the least developed countries including hundreds of millions of children live in slums. Slums are areas of broad social and health disadvantage to children and their families due to extreme poverty, overcrowding, poor water quality and sanitation, substandard housing, limited access to basic health and education services. The objective of this study was to assess the demographic and nutritional status of working slum children in Dhaka city.

Methods: This descriptive cross-sectional study was conducted at Moghbazar slum, situated in Dhaka city from July to December, 2013. A total of 200 slum children aged 6 to18 years whose parents' (either father or mother) voluntarily consented to allow their children participate in the study.

Result: Out of 200 slum children, $57(28.5 \%)$ were in the age group of $12-14$ years, among them $110(55.0 \%)$ were male. More than $50 \%$ never attended any kinds of formal school. Forty five percent children lived with their parents. Over half (26\%) of the slum children were engaged in beggary, $23 \%$ were van/rickshaw puller, $22 \%$ were rag-picker (Tokai), 10\% were cooli. Three-quarters of the children had medium work-load and $80 \%$ did 5-8 hours work per day sixty percent of the children had monthly income of Taka 1000-1500. In terms of BMI, one-third (33.5\%) was severely under-nourished, 55\% were of normal BMI and $11.5 \%$ were overweight and obese.

Conclusion: The study presented a gloomy picture (in terms of nutritional status) of working children in a selected slum within Dhaka city. Therefore, health related programmes should focus to improve the overall wellbeing of the working slum children.

Key words: Nutritional status, working slum children, occupation.
\end{abstract}

\section{INTRODUCTION:}

Children constitute a large segment of the world's population and, therefore, form a significant component of all human societies. ${ }^{1}$ There is a general tendency in society to view slum children as criminals, victims, or as sub-human figures but a significant portion of disadvantaged children live in the slums on account of acute impoverishment which is caused by social deprivation. ${ }^{2}$ Many children find works, like collecting the waste papers, cleaning cars or working as shoe shiners. Some engage in begging, pick-pocketing or sex pervert while others end up as drug addicts, who use cheap and easy accessed inhalants which cause irreversible brain damage. Furthermore, they have less access to basic amenities, such as,

\section{Authors' information:}

${ }^{\prime}$ Dr. Md. Nurul Amin, Assistant Professor, Department of Community Medicine, Rajshahi Medical College, Rajshahi \& Executive Editor, Ibrahim Cardiac Medical Journal, Ibrahim Cardiac Hospital \& Research Institute, Shahbag, Dhaka.

2 Dr. Shayela Farah, MBBS, MPH (DU), Assistant Professor, Department of Community Medicine, Dhaka Community Medical College, Moghbazar, Dhaka-1217

${ }^{3}$ Dr. Mohoshina Karim, MBBS, MPH (DU), Lecturer, Department of Community Medicine, Dhaka Community Medical College, Moghbazar, Dhaka.-1217

${ }^{4}$ Dr. Farhana Rahman, Assistant Professor (Pediatrics), Delta Medical College, Dhaka.

${ }^{5}$ Shitil Ibna Islam, MS in Environmental Science (KU) \& Health Economich (DU), Research Officer, Ibrahim Cardiac Hospital \& Research Institute, Shahbag, Dhaka, Bangladesh.

Correspondence: Dr. Shayela Farah, Phone:+8801716143491 E-mail: shayelafarah@yahoo.com 
health, education or food. ${ }^{3}$ Bangladesh is a country of South Asia with 1, 47,570 sq. km of geographical area and 146.6 million people making it world's seventh most densely populated country. ${ }^{4}$

Dhaka is the capital city of Bangladesh and one of the most densely-populated \& rapidly expanding mega-cities in the world. Unfortunately, the expansion and growth are not well planned. It is estimated that every year 300,000 to 400,000 new migrants come to city from different parts of the country. As a result, every ten years the population of Dhaka is doubling. Many slum dwellers are illiterate, live in unhygienic conditions, eat unhealthy food and drink unsafe water. These conditions create many health problems. Overcrowding \& unsanitary conditions facilitate the transmission of disease-including pneumonia and diarrhoea, the two leading killers of children (younger than 5 years) worldwide. Outbreaks of measles, tuberculosis and other vaccine preventable diseases are also more frequent in these areas, where population density is high and immunization levels are low. ${ }^{5}$

It has been recognized that infants, children and women of the reproductive age constitute the most vulnerable group from the stand point of nutrition. Malnutrition is the outcome of many complex biological and social processes. The roots of malnutrition run deep into its social soil and it is a cause of concern. ${ }^{6}$ Since children have the rights to survival, adequate health care and a standard of living that supports their full development. Research on urban slum dwellers, specially, on nutrition is very relevant and deserve in-depth studies. This could help explain many of the interrelated variables which come into play in explaining the prevailing situation amongst the urban slum dwellers. The purpose of the study was to assess the demographic and nutritional situation of working slum children in slum environment in Dhaka city.

\section{METHODS:}

This descriptive cross-sectional study was conducted at Moghbazar slum situated near the Dhaka Community Medical College Hospital. The study duration was six months from July to December, 2013 to assess the situation of working slum children in Dhaka city. A house-to-house survey was conducted and a total of 200 working children aged 6 to 18 years were enrolled using purposive sampling technique. Consent regarding their participation in the study was, however, taken from their parents. The children were interviewed and information regarding the age, education, occupation, monthly family income, working conditions and nutritional status of their children were collected both from the parents and children. Height was measured without shoes to the nearest centimeter using a ruler attached to the wall, while weight was measured to the nearest $0.1 \mathrm{~kg}$ on a manually-adjusted scale with the subject wearing school ordinary dress and no shoes. Then data were collected from the respondents by face-to-face interview using a semi-structured questionnaire (Research Instrument or Tool). Using weight and height data, body mass index (BMI) was calculated with the help of formula BMI $=$ (weight in $\mathrm{kg}$ )/ (height in sq-meter).

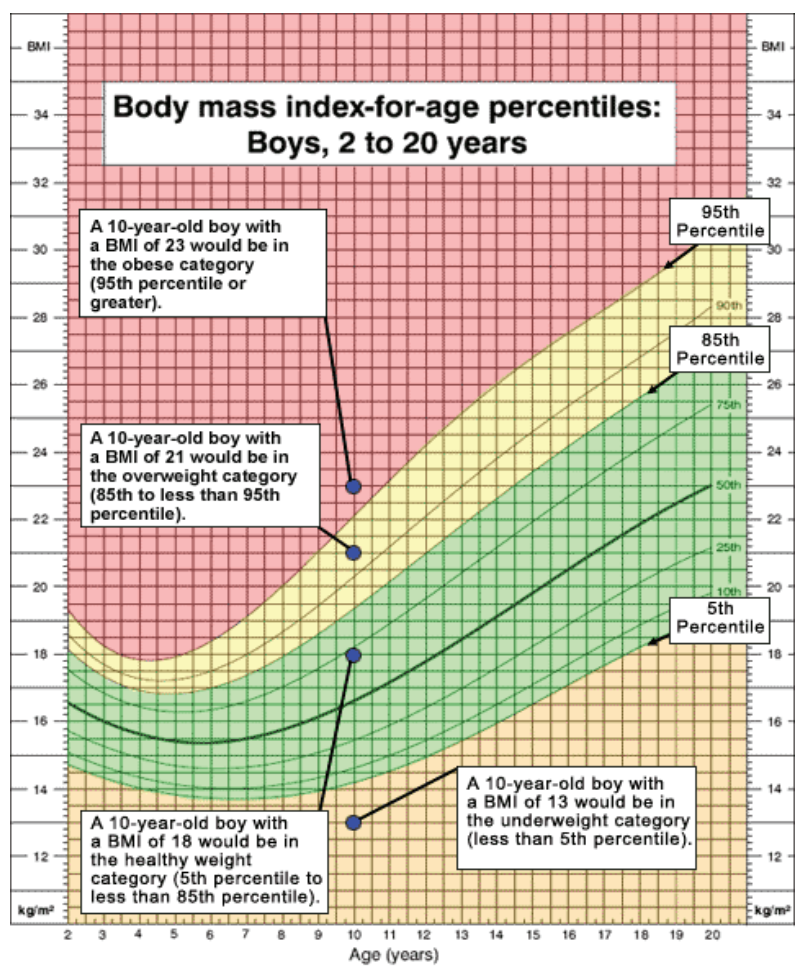

Fig. 1 : Body mass index-for-age percentiles (Adapted from CDC, Atlanta) 
As BMI of children and adolescents is age- and sex-specific, calculated BMI were plotted on Growth-chart [developed and recommended by Centre Disease Control (CDC), Atlanta] to find the percentile. Then the nutritional status of the individual respondents was determined as follows:

Table I. Nutritional status based on BMI-for-age percentiles (Adapted from CDC, Atlanta)

\begin{tabular}{|l|l|}
\hline Nutritional status & Percentile range \\
\hline Underweight & $<5^{\text {th }}$ Percentile \\
\hline Normal & 5 th to $<85^{\text {th }}$ Percentile \\
\hline Overweight & $85^{\text {th }}$ to $<95^{\text {th }}$ Percentile \\
\hline Obese & $\geq 95^{\text {th }}$ Percentile \\
\hline
\end{tabular}

Data were processed and analysed using SPSS, version 23. All analyzed data were presented in the form of frequency and percentages.

\section{RESULTS:}

Out of 200 slum children, $57(28.5 \%)$ were in the age range $12-14$ years, $45(22.5 \%)$ in $6-8$ years and $42(21.0 \%)$ were in $15-17$ years. Among them $110(55.0 \%)$ were male and the rest female. More than 50\% children never attended in school, 30\% had incomplete primary level education and $16.5 \%$ completed primary level. Forty five percent children lived with their parents, $27 \%$ lived with their mothers only and $22 \%$ lived alone. Majority (83\%) had 3-5 family members (Table II).

The children were found to be engaged in a wide range of activities, which included among others Tokai (rag-picker) (22\%), van/rickshaw puller $(23 \%)$, beggar $(26 \%)$, Cooli $(10 \%)$ at the railway station or 'launch ghat' etc. Seventy five percent of the children had medium work-load and $80 \%$ did 5-8 hours work per day. Sixty percent had monthly income of Taka 1000-1500, 30\% Taka < 1000 and $10 \%$ Taka > 1500 (Table III). In terms of nutritional status (BMI), one-third (33.5\%) was severely undernourished, 55\% were of normal nutritional status, $9 \%$ were overweight and $2.5 \%$ obese (Fig 2).

\begin{tabular}{|c|c|c|}
\hline Socio-demographic characteristics & Frequency & Percentage \\
\hline \multicolumn{3}{|l|}{ Age (years) } \\
\hline $6-8$ & 45 & 22.5 \\
\hline $9-11$ & 40 & 20.0 \\
\hline $12-14$ & 57 & 28.5 \\
\hline $15-17$ & 42 & 21.0 \\
\hline$>17$ & 16 & 8.0 \\
\hline \multicolumn{3}{|l|}{ Sex } \\
\hline Male & 110 & 55.0 \\
\hline Female & 90 & 45.0 \\
\hline \multicolumn{3}{|l|}{ Education } \\
\hline Never attended any school & 102 & 51.0 \\
\hline Primary incomplete & 60 & 30.0 \\
\hline Primary complete & 33 & 16.5 \\
\hline Secondary incomplete & 05 & 2.5 \\
\hline \multicolumn{3}{|l|}{ Living with } \\
\hline Both Parents & 90 & 45.0 \\
\hline Mother Only & 54 & 27.0 \\
\hline Father Only & 02 & 1.0 \\
\hline Alone & 44 & 22.0 \\
\hline Others & 10 & 5.0 \\
\hline \multicolumn{3}{|l|}{ Family members } \\
\hline$<3$ & 14 & 7.0 \\
\hline $3-5$ & 166 & 83.0 \\
\hline$>5$ & 20 & 10.0 \\
\hline
\end{tabular}

Table III. Working status of the slum children $(n=200)$

\begin{tabular}{lcc|}
\hline Work-related variables & Frequency & Percentage \\
\hline Occupation & & \\
$\quad$ Beggary & 52 & 26.0 \\
Domestic help & 15 & 7.5 \\
Rag-pickers (Tokai) & 44 & 22.0 \\
Day labour & 15 & 7.5 \\
Sex work & 08 & 4.0 \\
Rickshaw/van-pulling & 46 & 23.0 \\
Transport work/help (Cooli) & 20 & 10.0 \\
Work-load & & \\
Normal & 34 & 17.0 \\
Medium & 150 & 75.0 \\
Heavy & 16 & 8.0 \\
Working hours & & \\
$5-8$ & 160 & 80.0 \\
$>8$ & 40 & 20.0 \\
Personal income (TK) & & \\
$<1000$ & 60 & 30.0 \\
$1000-1500$ & 120 & 60.0 \\
$>1500$ & 20 & 10.0
\end{tabular}




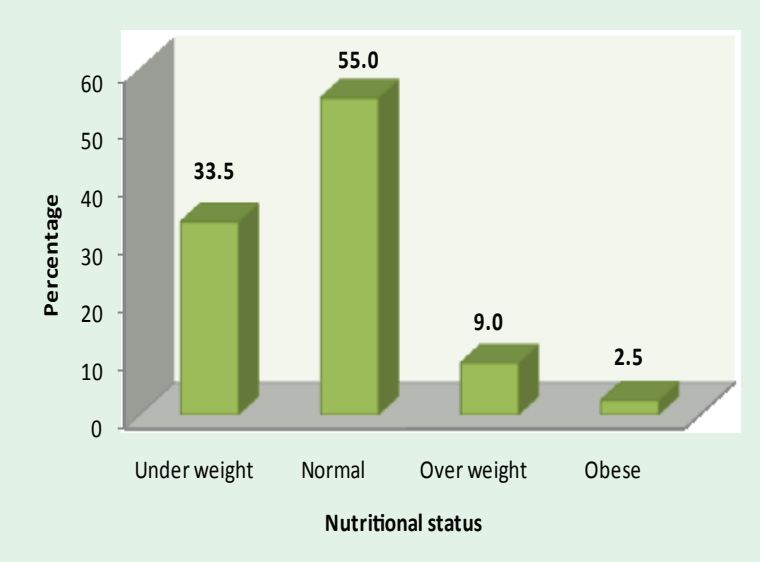

Fig. 2: Distribution of children by their nutritional status $(n=200)$

\section{DISCUSSION:}

Growth of urban population is always accompanied by the growth of slums, which poses threat to the health of urban population, particularly, the health of the children. ${ }^{7}$ In the present study out of 200 slum children, $57(28.5 \%)$ were in the age range of $12-14$ years, $45(22.5 \%)$ in the range of $6-8$ years and $42(21.0 \%)$ were in $15-17$ years which bears consistency with the findings of Ahmad $^{8}$ (31\% were $8-10$ years, $34 \% 11-13$ years and $35 \%$ 14-18 years of age).

The present study demonstrated that over half $(51 \%)$ of the children never attended in any kinds of formal education \& $15(33.0 \%)$ had incomplete primary education. Khatun \& associates ${ }^{2}$ conducted a study in Khulna city where one-fourth (25\%) of the children were illiterate, $57 \%$ completed up to Grade-III and only 3\% completed up to GradeVIII. Forty five percent children lived with their parents, $27 \%$ with mothers only and $22 \%$ alone. These findings are consistent with the findings of "The Chetona Bikash Kendra (CBK)" where 45\% live with their parents, $18 \%$ maintained contact with parents and $24 \%$ had no contact with parents. ${ }^{8}$ Majority of children lived with 3-5 family members with average family member being $5 .{ }^{9}$ Conception goes that population explosion rate is high in slum. But the study found that they prefer to have small-family like other non-city slum dwellers for better living.
UNICEF estimates that around $16 \%$ of children aged 5-14 years in developing countries are involved in child labour. ${ }^{10}$ ILO estimates that around 215 million children under 18 work around the world; many of them being full-time. In Sub-Saharan Africa 1 in 4 children aged 5-17 works, compared to 1 in 8 in Asia-Pacific and 1 in 10 in Latin America are engaged in child-labour. ${ }^{11}$ Even though the prevalence of child labour is falling in recent years everywhere, apart from Sub-Saharan Africa, ${ }^{12}$ it continues to harm the physical and mental development of children and adolescents and interfere with their education. ${ }^{10}$

The slum children were found engaged in a variety of activities, which mong others include rag-picking, van/rickshaw pulling, beggary, assisting passengers in carrying their luggage in "railway station" or "launch-ghat" (cooli) etc. Working children are involved in many different types of work, often for little or no pay. Some children work within their own homes, engaged in domestic chores and small family businesses. Others work outside their homes, in small shops, factories, restaurants, tanneries, waste-dumps and on the streets. Most working children are employed for an average 8 to 12 hours a day. Many children involve working in hazardous conditions that endanger their physical or mental health and moral development through unsafe environments, dangerous duties or overly- long working hours. ${ }^{13}$

Three-quarters (75\%) had medium work-load and $80 \%$ of them did 5-8 hours work per day and most of their income was 1000-1500 Tk per month which is in line with the results of Khatun et $\mathrm{al}^{2}$. Malnutrition makes a central contribution (up to $56 \%$ ) to child mortality worldwide and is a recognised problem in informal settlements. ${ }^{14}$ In the present study, $(33.5 \%)$ children were severely under-nourished, $55 \%$ were normal and $11.5 \%$ overweight or obese. Compared with their urban counterparts, children in slums are more likely to be undernourished and stunted ${ }^{15,16}$ which might be due to prolonged or recurrent episodes of hunger or specific nutritional deficiencies (e.g., caloric, protein, micronutrient), and also might be due to persistent or recurrent ill-health. ${ }^{17}$ 
In countries where a large proportion of the urban landscape is covered with slums, the rates of malnutrition and mortality amongst children are high, particularly in sub-Saharan Africa and South Asia. This is clearly linked to inequalities in access to shelter, health care, employment \& education. In most of the developing countries, 2 out of 5 slum children are malnourished, a ratio that is twenty times higher than that of developed countries. ${ }^{18}$

\section{CONCLUSION:}

The findings of this cross-sectional study presented a gloomy picture (in terms of demographic and nutritional status) of working children in a selected slum in Dhaka city. A large-scale study addressing the variables of interest is desirable for gaining further insight.

\section{REFERENCES:}

1. Pagare D, Meena GS, Singh MM, Saba R. Risk factors of substance use amongst street children from Dehli. Journal of the Indian Academy of Pediatrics 2004;41 (3):221-25.

2. Khatun MT, Jamil H. Life Style of the Street Children. Bangladesh Research Publications Journal 2013;9(1) :50-56.

3. Ahmed S. Bangladesh: Moving towards universal birth registration. The IRIN (e newspaper) [Internet]. DHAKA, 15 July 2008 [Cited 14/06/2016 11:51 AM] Availablefrom:http://www.irinnews.org/report/79258/ bangladesh-moving-towards-universal-birth-registration.

4. BBS. Statistical Pocket Book. Bangladesh Bureau of Statistics. 2009.

5. SOW 2012-Main Report_EN_13 Mar 2012.

6. Haque $M$, Bhuiyan $R$, Naser MA, Arafat $Y$, Roy SK, Khan $\mathrm{ZH}$. Nutritional Status of Women Dwelling in Urban Slum Area. J Nutr Health Food Eng 2014;1(3):00014. Availablefrom:http://dx.doi.org/10.15406/jnhfe. 2014.01 .00014$.

7. Kavitha N. Are Slum Children at High Risk of Under Nutrition, Anemia and Childhood Morbidity? Evidence from India. Ind J Comm Health 2014;26(2):124-31.

8. Ahmad M: Education For Street Children: A Case Study of Chetona Bikash Kendra; Community Development Library (CDL), Annual Activity Report 2003. Dhaka.

9. Democracywatch. A Study on Situation of Girl Children of Slums in Dhaka City, 2010.
10. UNICEF 2011 State of the World's Children. Adolescence An Age of Opportunity United Nations Children's Fund (UNICEF). February 2011.

11. Saltillo United Nations Simulation [Internet]. Suns 2013 [cited 14/06/2016 12:14 PM]. Available able from: http://colamsuns2013.wix.com/suns-2013?_escaped_ fragment_=background-papers-unicef/c1q4y

12. UNICEF. 2015 http://www2.unicef.org:60090/protection/ 57929_58009.html

13. Education_for_Working_Children_(BEHTRUWC). pdf.. Availableat:https://www.scribd.com/document/13511 0509/ Education-for-Working-Children-BEHTRUWC

14. Swaminathan $\mathrm{H}$, Mukherji A. Slums \& malnourishment: evidence from women in India. Am J Public Health 2012;102:1329-35.

15. Fotso JC. Child health inequities in developing countries: differences across urban and rural areas. Int J Equity Health 2006;5:9.

16. Sverdlik A. Ill-health and poverty: a literature review on health in informal settlements. Environ Urban 2011; 23:123-55.

17. Bhutta ZA, Chopra M, Axelson H, Berman P, Boerma T, Bryce J, Bustreo F, et al. Countdown to 2015 decade report (2000-10): taking stock of maternal, newborn, and child survival. Lancet 2010;375:2032-44.

18. Urban Features: Children, Slums' First Casualties, UN-HABITAT. Available from: www.unhabitat.org. 